\title{
RESEARCH
}

\section{COENZYME Q10 EFFECTIVELY PREVENTS AGE-RELATED HEARING LOSS IN C57BL/6 MICE}

Turkish Journal of Geriatrics DOI: 10.31086/tjgeri.2021.219 2021; 24(2): 235-243

- Togay MÜDERRis 1

-Ergün SEVIL ${ }^{2}$. .

- Atiye Seda YAR SAĞLAM ${ }^{3}$

- Mehmet Ali BABADEMEZ ${ }^{4}$

CORRESPONDANCE

\section{${ }^{2}$ Ergün SEVIL}

Alanya Alaaddin Keykubat University Faculty of Medicine, Otorhinolaryngology, Head and Neck Surgery, Alanya, Turkey

\section{Phone: +905363104655 \\ e-mail: drergunsevil@yahoo.com}

Received: Mar 27, 2021

Accepted: May 16, 2021

${ }^{1}$ Izmir Bakircay University Faculty of Medicine, Otorhinolaryngology, Head and Neck Surgery, Izmir, Turkey

${ }^{2}$ Alanya Alaaddin Keykubat University Faculty of Medicine, Otorhinolaryngology, Head and Neck Surgery, Alanya, Turkey

${ }^{3}$ Gazi University Faculty of Medicine, Medical Biology and Genetics, Ankara, Turkey

${ }^{4}$ Yildirim Beyazit University Faculty of Medicine, Otorhinolaryngology, Head and Neck Surgery, Ankara, Turkey

\section{Abstract}

Introduction: Presbycusis is characterized by gradual, progressive sensorineural hearing loss. The aim of this study is to evaluate the effects of coenzyme $\mathrm{Q} 10$ in the prevention and treatment of age-related hearing loss.

Materials and Method: Thirty-two C57BL/6 mice were assigned into four groups as early treatment, late treatment, control and sham control. Treatment was started at three months of age in the early treatment group and at six months in the late treatment group. The auditory brainstem test was performed once every three months. At the end of the study period, the cochleae of the animals were harvested, and Bcl-2, Bcl-xL, iNOS, COX-2, NF-kB, Bax, and Bak levels were analyzed with real-time polymerase chain reaction.

Results: The hearing thresholds of the mice in the early treatment group were better than those of the other groups $(p<0.001)$. Hearing levels were also better in the late treatment group than control groups, but the difference was not significant $(p>0.05)$. The threshold shift in the early treatment group was significantly lower than the control groups $(p<0.001)$. The mRNA expression levels of proapoptotic genes Bax and Bak were lower $(p<0.05)$, antiapoptotic genes Bcl-2 and Bcl-xL were higher $(p<0.05)$, and the NF-kB, COX-2, and iNOS genes, which play a role in inflammation, were lower $(p<0.05)$ in the early treatment group.

Conclusion: These results suggest that coenzyme $\mathrm{Q} 10$ effectively attenuates the presentation of age-related hearing loss, especially when started before the onset of hearing loss.

Key Words: Presbycusis; Evoked Potentials, Auditory, Brain Stem; Oxidative Stress; Antioxidants 


\section{INTRODUCTION}

Age-related sensorineural hearing loss or presbycusis is a slow, progressive hearing loss that develops with age. Presbycusis is characterized by decreased hearing, difficulty in distinguishing speech in noisy environments, the slowing of acoustic stimuli in the brain, and the deterioration of sound localization. Hearing loss typically occurs at high frequencies (1, 2).

Oxidative damage, which is the cause of free radical damage, is perhaps the most fundamental cause of age-related pathologies in the biological aging of cells. Oxidative damage is also an important intrinsic factor in the pathogenesis of presbycusis. Free radicals, which occur as a by-product during the normal activities of cells, cause mitochondrial genome deletions. Considering the contribution of oxidative damage in the pathogenesis of presbycusis, an age-related condition, it can be thought that antioxidants may prevent the onset or progression of the disease. Therefore, the role of many antioxidants, including folate, melatonin, ascorbic acid, alpha lipoic acid, and carnitine, have been investigated for the prevention or treatment of presbycusis, as it has been suggested that various antioxidants may play a role in the prevention and treatment of age-related hearing loss $(3,4)$.

During inflammation, an increase in the expression of cyclooxygenase-2 (COX-2) and inducible nitric oxide synthase (iNOS) genes was observed in monocytes, macrophages, synovial cells, fibroblasts, chondrocytes, and endothelial cells, which are stimulated by different cytokines, growth factors, or mitogens. In hearing loss, studies have shown that there is an increase in various inflammatory mediators, especially COX-2 and iNOS, and coenzyme Q10 (CoQ10), which causes a significant decrease in the amount of these mediators $(5,6)$.

Apoptotic cell death, which is an important mechanism for maintaining the balance between the life and death of cells, is stimulated or suppressively regulated by various proteins. Some cellular molecules, such as caspase enzymes and intracellular Bcl-2 gene family proteins ( $\mathrm{Bcl}-2, \mathrm{Bcl}-\mathrm{xL}, \mathrm{Bak}$, and $\mathrm{Bax}$ ), are involved in the regulation of apoptosis. In mouse experiments, it has been shown that apoptotic cell death occurs earlier in mice with sensorineural hearing loss (7).

The aim of this study was to evaluate the possible protective, retarding and/or therapeutic effects of CoQ10 on presbycusis in C57BL/6 mice. In addition, after presbycusis development and CoQ10 administration, real-time polymerase chain reaction (PCR) examination of the cochlear tissues obtained from mice was conducted to determine the changes in mRNA expression levels of the iNOS, COX-2, and nuclear factor kappa B (NF-kB) genes, which are effective in inflammation, $\mathrm{Bcl} 2, \mathrm{Bcl}-\mathrm{xL}, \mathrm{Bax}$, and Bak genes, which play a role in the formation of apoptosis.

\section{MATERIALS AND METHODS}

\section{Laboratory animals}

The study sample comprised 32 C57BL/6 healthy male mice, each weighing 20-25 gr and aged three months. The mice were procured from Bilkent University Laboratory Animal Breeding and Experimental Research Center and brought to Gazi University Laboratory Animal Breeding and Experimental Research Center, where the experiment was conducted. The animals were housed in plastic cages at a temperature of $23^{\circ} \pm 2^{\circ} \mathrm{C}$, with a 12 hours light/dark cycle, and had free access to food and water before and during the experiment. Ethics committee approval was obtained for the study from Animal Experiments Local Ethics Committee (G.Ü.ET-18.067, Number: 66332047-604.01.02).

The mice were separated into four experimental groups of eight animals in each group: 1) Control Group, 2) Sham Control Group, 3) Early Treatment Group, and 4) Late Treatment Group. The CoQ10 and Dimethyl Sulfoxide (DMSO) used in the exper- 
iment were supplied by Sigma-Aldrich (Darmstadt, Germany).

\section{Anesthesia}

The mice were anesthetized with an intraperitoneal injection of ketamine $(45 \mathrm{mg} / \mathrm{kg})$ and xylazine $(2.5 \mathrm{mg} / \mathrm{kg})$ during the ABR measurements. The depth of anesthesia was measured with pedal reflex, and to maintain anesthesia, a half dose of this cocktail was administered as required. At the end of the study, the animals were sacrificed under the same anesthetic protocol.

\section{Study protocol}

Sample size was determined based on a desired power of 0.8, a desired alpha of 0.05, and an estimated size effect delta of approximately 1.4, based on preliminary data. The mice were randomly separated into four groups and treated as follows: Group $1(n=8)$ as the control group received no drugs; Group $2(n=8)$ as the sham control group was administered dimethyl sulfoxide (DMSO) at three months of age to evaluate the possible effects on hearing of DMSO, the substance in which CoQ10 was dissolved; Group $3(n=8)$ as the early treatment group was administered $\mathrm{CoQ} 10$ starting at three months of age; and Group $4(n=8)$ as the late treatment group received $\mathrm{CoO} 10$ starting at six months of age.

CoQ10 was purchased from Sigma Aldrich (St. Louis, MO), dissolved in 30\% DMSO $(20 \mathrm{mg} / \mathrm{ml})$ (Sigma Aldrich, St. Louis, MO), and added to the drinking water of the mice so that an approximate daily dosage of $500 \mu \mathrm{\gamma} / \mathrm{kg}$ for each mouse was maintained. A new solution was prepared weekly during the study period to ensure the stability of CoQ10. The mice were weighed every week, and the dose of the CoQ10 was adjusted according to the weight of the mice, if necessary. Additionally, 30\% DMSO was freshly prepared on a weekly basis and added to the drinking water of the sham control group.

\section{Auditory Brain Stem Response}

The auditory brainstem response (ABR) measure- ments were taken using a two channel Neuro-audio ${ }^{\circledR}$ ABR device (Neurosoft, Ivanova, Russia). Body temperature was maintained at $37^{\circ} \mathrm{C}$ by placing the animal on a thermal blanket. After anesthesia, ABR measurements were taken from both the right and left ears of each mouse; two traces were registered for each ear to control the repeatability of the response. Frequency-specific tone bursts (TB) at 4000 $\mathrm{Hz}, 8000 \mathrm{~Hz}, 12000 \mathrm{~Hz}$, and $16000 \mathrm{~Hz}$ were used as the auditory stimulus. The analysis time for the ABR recording was $20 \mathrm{~ms}, 100-2000 \mathrm{~Hz}$ for TB stimuli, 30-3000 Hz for click stimuli, and a band-pass filter and alternating polarity were selected. The repetition rate was set as $21 / \mathrm{sec}$, and the average was 1024 sweeps. Thresholds were determined starting from the maximum outputs (110-118 dB SPL) and decreasing the stimuli by $5 \mathrm{~dB}$; stimulus intensity was reduced until waves in reproducible morphology could not be detected.

\section{Gene Analysis in Cochlea Homogenates}

To examine the effect of CoQ10 following the termination of the experiment at the end of 12 months, cochlear tissue was taken from the inner ear of each mouse to determine the expression levels of iNOS, COX-2, NF-kB, Bcl-2, Bcl-xL, Bax, and Bak genes, which are effective in inflammation and apoptosis, using real-time PCR analysis. The cochleae of both ears were removed under a dissecting microscope and crushed.

Total RNA was isolated from fresh cochlear tissues using Trizol reagent (Life Technologies, CA, USA) and stored at $-80^{\circ} \mathrm{C}$ until use. RNA concentration was measured using a NanoDrop 1000 spectrophotometer (Thermo Fisher Scientific). One microgram of total RNA was used for gene-specific reverse transcription polymerase chain reaction (RT-PCR) using a Transcriptor High Fidelity cDNA Synthesis Kit (Roche, Mannheim, Germany). The cDNA samples were kept at $-80^{\circ} \mathrm{C}$ until PCR analysis. Gene expression level studies were determined using the quantitative real-time PCR (qRT-PCR) method using a Light Cycler-480TM (LC) device 


\section{(Roche, Germany).}

\section{Statistical Analysis}

From the real-time PCR analysis results of RNA obtained after RNA isolation from the cochlea tissue at the end of the experiment, differences in iNOS, COX-2, NF-kB, Bcl-2, Bcl-xL, Bak, and Bax mRNA expression levels were compared with the REST (2009 V2.0.13) statistics program (8). For the statistical evaluation of hearing loss between treated and untreated mice, SPSS V. 22 software was used (SPSS Inc., Chicago, IL, USA). The ABR results were compared with the Kruskal-Wallis analysis of variance (ANOVA) to determine the significance of the difference between the groups. The post hoc Tukey method of analysis was used to verify statistical significance; a value of $\mathrm{p}<0.05$ was considered statistically significant.

\section{RESULTS}

All 32 mice included in the study completed the study period of 12 months. There was no significant difference with respect to the pre- and post-study weights of the mice $(p=0.520)$.

The ABR results of the mice at the beginning of the study, when the mice were three months old, were evaluated using Kruskal-Wallis ANOVA, and there was no statistically significant difference between the experimental groups in terms of $A B R$ results at all frequencies $(p=0.810)$. There was no significant difference between the groups with respect to the ABR results in the third month of the experiment (mice at six months of age) $(p=0.635$,

Table 1).

In the tests performed in the sixth month of the experiment, the ABR thresholds of the early treatment group were significantly lower than those of the control, sham control, and late treatment groups ( $p=0.007$ ). However, there was no significant difference in the ABR thresholds between the late treatment, control, and sham control groups ( $p$ $=0.354$, Table 2 ). In comparison of the ABR thresholds between the third and sixth months of the experiment, no significant difference was determined in the ABR thresholds in the early treatment group $(p=0.264)$. In the late treatment, control, and sham control groups, the ABR thresholds were found to be significantly higher at six months than at three months ( $p=0.004$ for the late treatment group, $p$ $=0.008$ for the control group, and $p=0.007$ for the sham control group).

In the tests performed in the ninth month of the experiment (when the mice were 12 months old), the mean ABR thresholds of the early treatment group were determined to be lower than those of the control and sham control groups at all frequencies $(p<0.001)$. The ABR thresholds of the late treatment group were lower than those of the

Table 1. Mean ABR thresholds of the mice according to stimulus frequencies in the third month of the study (values in $d B$ $\mathrm{SPL})$.

\begin{tabular}{|c|c|c|c|c|c|}
\hline $\begin{array}{l}\text { Frequency } \\
(\mathrm{kHz})\end{array}$ & $\begin{array}{c}\text { Control } \\
(\text { mean } \pm S D)\end{array}$ & $\begin{array}{l}\text { Sham Control } \\
\text { (mean } \pm \text { SD) }\end{array}$ & $\begin{array}{c}\text { Early } \\
(\text { mean } \pm \text { SD) }\end{array}$ & $\begin{array}{c}\text { Late } \\
(\text { mean } \pm S D)\end{array}$ & $p$ \\
\hline 4 & $44,375 \pm 4,973$ & $43,75 \pm 5,313$ & $40 \pm 5,212$ & $41,875 \pm 4,892$ & 0,613 \\
\hline 8 & $18,125 \pm 3,323$ & $20,625 \pm 3,967$ & $17,5 \pm 4,112$ & $18,125 \pm 4,033$ & 0,512 \\
\hline 12 & $16,875 \pm 3,612$ & $17,5 \pm 3,453$ & $16,875 \pm 3,834$ & $19,375 \pm 3,673$ & 0,472 \\
\hline 16 & $27,5 \pm 4,345$ & $28,125 \pm 5,173$ & $26,25 \pm 4,873$ & $28,75 \pm 4,364$ & 0,520 \\
\hline
\end{tabular}


Table 2. Mean ABR thresholds of the mice at the sixth month of the study by frequency of stimulus (values in dB SPL)

\begin{tabular}{|c|c|c|c|c|c|c|}
\hline $\begin{array}{c}\text { Frequency } \\
(\mathbf{k H z})\end{array}$ & $\begin{array}{c}\text { Control } \\
(\mathrm{mean} \pm \text { SD) }\end{array}$ & $\begin{array}{c}\text { Sham Control } \\
(\text { mean } \pm \text { SD) }\end{array}$ & $\begin{array}{c}\text { Early } \\
(\text { mean } \pm \text { SD) }\end{array}$ & $\begin{array}{c}\text { Late } \\
\text { (mean } \pm \text { SD) }\end{array}$ & $\mathbf{p}^{*}$ & $\mathbf{p}^{* *}$ \\
\hline 4 & $51,25 \pm 8,873$ & $51,875 \pm 9,412$ & $42,5 \pm 10,112$ & $49,375 \pm 10,883$ & 0,005 & 0,312 \\
\hline 8 & $24,375 \pm 3,323$ & $26,25 \pm 3,967$ & $20 \pm 4,112$ & $25,625 \pm 4,033$ & 0,007 & 0,245 \\
\hline 12 & $23,75 \pm 3,612$ & $23,125 \pm 3,453$ & $19,375 \pm 3,834$ & $25 \pm 3,673$ & 0,008 & 0,564 \\
\hline 16 & $34,375 \pm 4,345$ & $35 \pm 5,173$ & $30 \pm 4,873$ & $35,625 \pm 4,364$ & 0,004 & 0,320 \\
\hline
\end{tabular}

$\mathrm{P}^{*}$ : Comparison of early treatment group with other groups

$\mathrm{p}^{\star \star}$ : Comparison of late treatment. control and sham control groups

control and sham control groups, but the difference was not statistically significant $(p>0.05)$. The ABR thresholds of the early treatment group were lower than those of the late treatment group. This difference was significant at $12 \mathrm{kHz}$ and $16 \mathrm{kHz}(p=0.004$ and $p=0.006$, respectively), and not significant at 4 $\mathrm{kHz}$ and $8 \mathrm{kHz}$ (Table 3).

The last ABR threshold data obtained at the end of the study, just before the mice were sacrificed, are presented in Table 4. The ABR thresholds in the early treatment group were significantly better than those of the late treatment, control, and sham control groups $(p=0.000)$. The mean difference in $A B R$ thresholds between the early and late treat- ment groups was $12.5 \mathrm{~dB}$ to $21.25 \mathrm{~dB}$, the mean difference of $A B R$ thresholds between the early treatment and the control group was $18.75 \mathrm{~dB}$ to 30 $\mathrm{dB}$, and the mean difference in ABR thresholds between the early treatment and sham control groups ranged from $20.625 \mathrm{~dB}$ to $28.75 \mathrm{~dB}$. When the mean $A B R$ thresholds of the late treatment and the control group were compared, although the ABR thresholds of the late treatment group were better than those of the control group at all frequencies, the difference was not statistically significant ( $p=$ 0.102).

The ABR threshold changes that occurred from the beginning of the study to the 15th month were

Table 3. Mean ABR thresholds of the mice at the 12th month of the study by frequency of stimulus (values in dB SPL)

\begin{tabular}{|c|c|c|c|c|c|c|c|}
\hline $\begin{array}{c}\text { Frequency } \\
\text { (kHz) }\end{array}$ & $\begin{array}{c}\text { Control } \\
\text { (mean } \pm \text { SD) }\end{array}$ & $\begin{array}{c}\text { Sham Control } \\
\text { (mean } \pm \text { SD) }\end{array}$ & $\begin{array}{c}\text { Early } \\
\text { (mean } \pm \text { SD) }\end{array}$ & $\begin{array}{c}\text { Late } \\
\text { (mean } \pm \text { SD) }\end{array}$ & $\mathbf{p}^{*}$ & $\mathbf{p}^{* *}$ & $\mathbf{p}^{* * *}$ \\
\hline 4 & $61,875 \pm 9,673$ & $63,125 \pm 9,412$ & $47,5 \pm 8,122$ & $55 \pm 6,883$ & $\mathbf{0 , 0 0 0}$ & 0,102 & 0,312 \\
\hline 8 & $42,5 \pm 8,323$ & $41,25 \pm 7,967$ & $27,5 \pm 6,112$ & $35,625 \pm 5,433$ & $\mathbf{0 , 0 0 0}$ & 0,007 & 0,245 \\
\hline 12 & $41,25 \pm 8,612$ & $42,5 \pm 8,453$ & $28,75 \pm 7,834$ & $38,75 \pm 6,773$ & $\mathbf{0 , 0 0 0}$ & 0,090 & $\mathbf{0 , 0 0 4}$ \\
\hline 16 & $57,5 \pm 7,435$ & $56,25 \pm 8,137$ & $37,5 \pm 8,873$ & $48,125 \pm 7,844$ & $\mathbf{0 , 0 0 0}$ & 0,112 & $\mathbf{0 , 0 0 6}$ \\
\hline
\end{tabular}

$\mathrm{p}^{*}$ : Comparison of early treatment group with control groups

$p^{\star *}$ : Comparison of late treatment. control and sham control groups

$\mathrm{p}^{\star \star \star}$ : Comparison of early treatment group with late treatment group 
Table 4. Mean ABR thresholds of the mice at the end of the study by frequency of stimulus (values in $\mathrm{dB}$ SPL)

\begin{tabular}{|c|c|c|c|c|c|c|}
\hline $\begin{array}{l}\text { Frequency } \\
\qquad(\mathrm{kHz})\end{array}$ & $\begin{array}{c}\text { Control } \\
(\text { mean } \pm S D)\end{array}$ & $\begin{array}{c}\text { Sham Control (mean } \\
\pm \text { SD) }\end{array}$ & $\begin{array}{c}\text { Early } \\
\text { (mean } \pm \text { SD) }\end{array}$ & $\begin{array}{c}\text { Late } \\
(\text { mean } \pm \mathrm{SD})\end{array}$ & $p^{*}$ & $p^{* *}$ \\
\hline 4 & $75 \pm 9,563$ & $76,875 \pm 10,112$ & $56,25 \pm 9,132$ & $68,75 \pm 8,963$ & 0,000 & 0,070 \\
\hline 8 & $61,25 \pm 8,432$ & $60 \pm 10,067$ & $31,25 \pm 9,012$ & $52,5 \pm 7,542$ & 0,001 & 0,011 \\
\hline 12 & $58,75 \pm 8,723$ & $57,5 \pm 9,344$ & $32,5 \pm 8,123$ & $48,75 \pm 8,463$ & 0,000 & 0,090 \\
\hline 16 & $63,75 \pm 9,324$ & $63 \pm 9,248$ & $41,25 \pm 9,762$ & $55 \pm 8,732$ & 0,000 & 0,112 \\
\hline
\end{tabular}

$\mathrm{P}^{*}$ : Comparison of early treatment group with late treatment and control groups

$\mathrm{p}^{\star \star}$ : Comparison of late treatment group with control and sham control groups

also evaluated. The mean ABR threshold change in the control and sham control groups ranged from $34.375 \mathrm{~dB}$ to $46.25 \mathrm{~dB}(\mathrm{p}=0.935)$. The threshold change ranged between $14.375 \mathrm{~dB}$ and $16.875 \mathrm{~dB}$ in the early treatment group and between $28.75 \mathrm{~dB}$ and $37.5 \mathrm{~dB}$ in the late treatment group. The $A B R$ threshold changes in the early treatment group were lower than those of the control groups at all frequencies $(p=0.000)$. The final threshold change differences of the early and late treatment groups varied between $11.875 \mathrm{~dB}$ and $23.125 \mathrm{~dB}$. This difference was not significant at $4 \mathrm{kHz}(p=0.823)$, and the threshold change at 8,12 , and $16 \mathrm{kHz}$ was significantly lower in the early treatment group $(p=$ 0.000).

In the age-related hearing loss model, the mRNA expression levels of proapoptotic genes such as Bax and Bak, which may be responsible for increased apoptosis in cells, were determined to be significantly reduced $(p<0.05$ ) in the early treatment group compared to the control and sham control groups. The mRNA expression levels of antiapoptotic genes such as Bcl-2 and Bcl-xL increased significantly $(p<0.05)$ while the mRNA expression levels of iNOS, COX-2, and Nf-kB genes, which are the inflammatory mediators involved in inflammation, were statistically decreased $(p<0.05)$. In the late treatment group, it was determined that the mRNA expression levels of proapoptotic genes such as Bax and Bak decreased while the mRNA expression levels of antiapoptotic genes such as $\mathrm{Bcl}-2$ and $\mathrm{BCl}-\mathrm{xL}$ increased; however, these increases and decreases were not statistically significant $(p>0.05)$. In the late treatment group, it was observed that the mRNA expression levels of the inflammatory mediator's iNOS, COX-2, and Nf-kB decreased, which was similar to the early treatment group, but this decrease was not statistically significant $(p>0.05$, Figure 1).

\section{DISCUSSION}

Age-related hearing loss is a degenerative disease that affects millions of people around the world and can lead to isolation and depression by distancing people from their environment (9). Furthermore, once it has developed, age-related hearing loss rehabilitation is a highly expensive process requiring the use of rehabilitation centers, devices (hearing aids and cochlear implants), and other technologies (10). This places a heavy burden on social security institutions, and in countries such as Turkey, where such rehabilitation and devices are not fully covered by these institutions, the financial cost to the patient is also quite high (11). Therefore, the high prevalence, serious impact on the general health status and quality of life of elderly people, and the cost of rehabilitation to individuals or social security 
Figure 1. The effect of coenzyme $\mathrm{Q} 10$ on the relative mRNA expression levels of the target genes in the age-related hearing loss model.

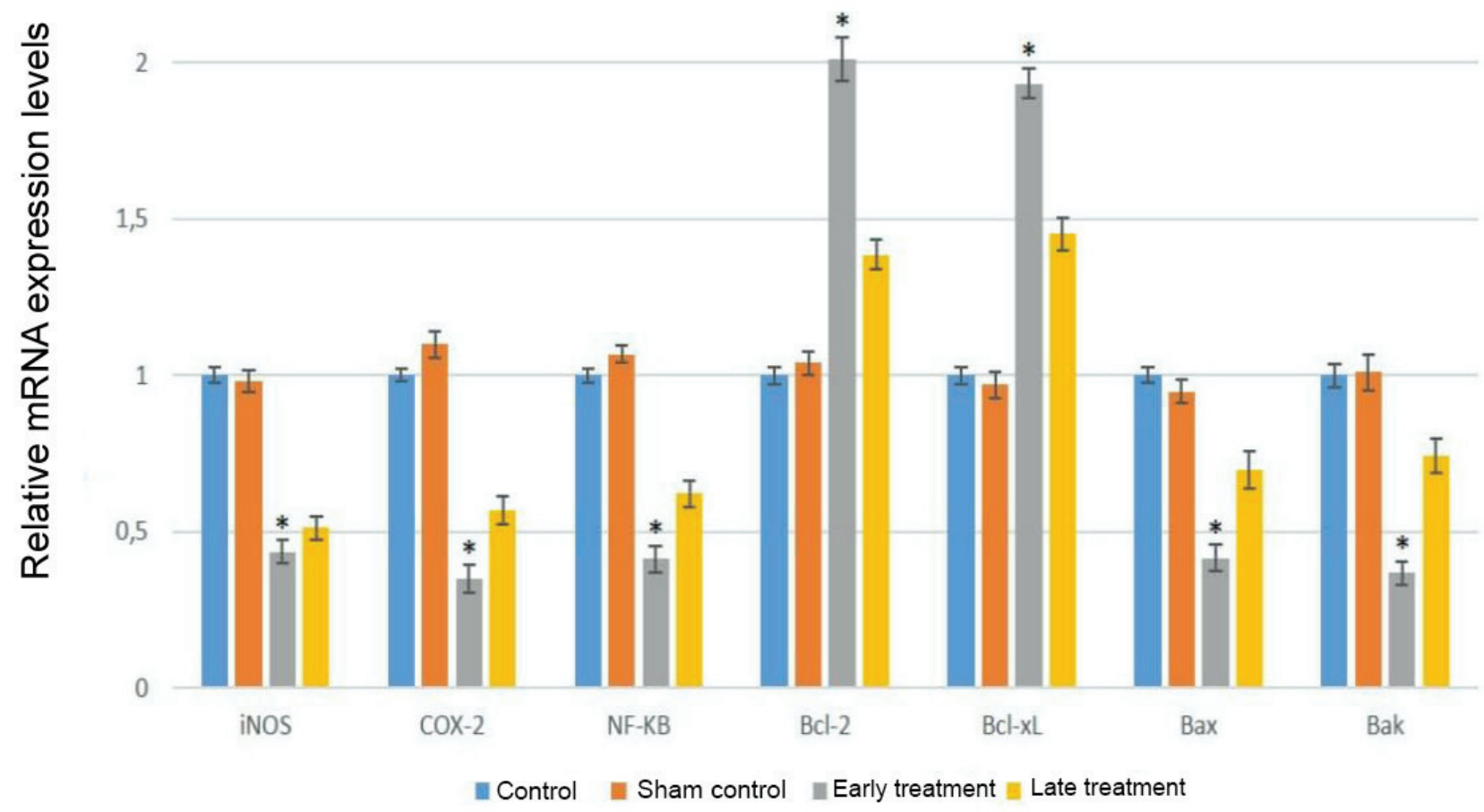

institutions make age-related hearing loss an important public health problem.

In cell aging, the most basic age-related pathology is oxidative damage caused by free radicals. It is now widely accepted that mitochondria are an important source of free radicals (ROS and RNS) and the main center of ROS/RNS-derived oxidative damage (12).

The current study findings, when evaluated in light of previous studies, show that antioxidant supplementation is more effective when initiated before the development of the genotypic changes responsible for age-related hearing loss. CoQ10 may have been less effective when treatment was initiated after the occurrence of age-related hearing loss, as the apoptotic process and inflammation had already begun at the molecular level. These re- sults are in line with those of previous studies (13, 14), which have demonstrated that antioxidants are effective in preventing but not treating age-related hearing loss. This is due to the inability of hair cells and spiral ganglion neurons to regenerate in mammals, so hearing cannot recover after damage. These findings are consistent with the current study hypothesis that CoO10 would be effective in preventing the development of age-related hearing loss.

Someya et al. showed that age-related hearing loss in C57BL/6J mice is mediated by Bak-dependent mitochondrial apoptosis and that oral supportive therapies containing mitochondrial antioxidants reduce cochlear cell death and prevent age-related hearing loss by lowering Bak expression in the cochlea (15). Similarly, in the current study, the ex- 
pression levels of proapoptotic genes in cochlear tissue, such as Bak and Bax, which play an important role in the pathway of mitochondrial apoptosis, were found to be significantly lower in mice that were given CoQ10 before the damage that caused hearing loss had developed in the inner ear, when compared to the late treatment and control groups. In parallel with this, the mRNA expression levels in the cochlear tissue of the $\mathrm{BCl}-2$ and $\mathrm{Bcl}-\mathrm{Xl}$ genes, which are antiapoptotic genes suppressing apoptosis, were also significantly higher when compared to the control and late treatment groups. These findings demonstrate that $\mathrm{CoO} 10$ reduces age-related changes by suppressing mitochondrial apoptosis-mediated cell death.

It has been clearly demonstrated that chronic inflammation plays a role in age-related intracellular damage in mammalian cells (16). In the current study, the expression levels of the iNOS, COX-2, and Nf-KB genes, which are mediators with important roles at different levels in the inflammatory process, were determined to be significantly lower in the cochlear tissues of the mice that received CoQ10 treatment in the early period compared to the other groups. In the late treatment group, although the expression levels of these genes were lower than in the control groups, the difference was not statistically significant. This shows that the administration of CoQ10 slows down the emergence of these processes before the development of chronic inflammatory processes that are responsible for age-related changes. Although the use of CoQ10 after these processes began to suppress the inflammatory processes to some extent, it could not cause a change at the clinical or molecular level.

The results of the current study showed that CoQ10 has a protective effect against age-related hearing loss even when used alone, which is in accordance with the findings of previous studies (17, 18). This effect was particularly pronounced when CoQ10 was used before the onset of hearing loss. This protective effect of CoO10 is due to the anti- oxidant properties revealed by its anti-inflammatory and antiapoptotic properties, as demonstrated by molecular studies. CoQ10 reduces the mRNA expression levels of the proapoptotic genes Bax and Bak, as well as the inflammatory mediators NF-KB, COX-2, and iNOS, while increasing the mRNA expression levels of antiapoptotic genes such as $\mathrm{Bcl}-2$ and $\mathrm{Bcl}-\mathrm{xL}$. These changes caused by $\mathrm{CoQ} 10$ slow down the aging process in the cochlea, thereby delaying the age-related changes.

In this study, functional and molecular studies revealed that $\mathrm{CoQ} 10$ treatment, which has antioxidant properties acting on many points in oxidative metabolism, can delay the emergence and reduce the severity of age-related hearing loss in C57BL/6 mice. This benefit was particularly evident in the early treatment group, where treatment was initiated before hearing loss developed. Furthermore, although the ABR results in the late treatment group were also better than those of the control groups, neither the changes at the molecular level nor the $A B R$ thresholds were significantly better compared to the control groups.

The most important limitation of this study was that an ABR device covering $32 \mathrm{kHz}$ could not be used due to technical limitations. Age-related hearing loss starts at high frequencies, so most, if not all, previous animal studies on this topic have included $32 \mathrm{kHz}$ ABR measurements. In addition, the expression levels of the genes examined in this study were investigated only in the cochlear tissue, which, although this is the first study in this scope in the literature, resulted in the examination of only the peripheral component of hearing loss at the molecular level. To be able to reveal the effects of CoQ10 on the changes that occur in the central pathways of hearing with regard to aging, there is a need for different histopathological and molecular studies of central hearing centers.

In conclusion, the results of this study demonstrated that starting CoQ10 treatment before the mechanisms leading to presbycusis development 
are effective in preserving hearing in mice. In the light of these findings, further studies are needed to determine the optimal dose and duration of treatment in humans. Human studies with a large num-

\section{REFERENCES}

1. JH Mills, CA Megerian CA, PR Lambert. Presbycusis and presbyastasis. In: James B. Snow, Phillip A. Wackym, (Eds). Ballenger's Otorhinolaryngology Head and Neck Surgery. 17th edition, BC Decker, Connecticut 2009, pp 333-42.

2. Matthews LJ, Lee FS, Mills Jh, Dubno JR. Extended high frequency thresholds in older adults. J Speech Lang Hear Res 1997; 40:208-14. (PMID: 9113871).

3. Selena E, Steven K, Tina C, Timothy S. A combination antioxidant therapy prevents age-related hearing loss in C57BL/6 mice. Otolaryngol Head Neck Surg 2010; 143:429-434. (PMID: 20723783).

4. Derin A, Agirdir B, Derin N et al. The effects of L-carnitine on presbycusis in the rat model. Clin Otolaryngol Allied Sci 2004; 29(3):238-41. (PMID: 15142068).

5. Kim JM, Park E. Coenzyme $\mathrm{Q} 10$ attenuated DMH-induced precancerous lesions in SD rats. J Nutr Sci Vitaminol (Tokyo) 2010; 56(2):139-44. (PMID: 20495296).

6. Wang X, Meng $\mathrm{Q}$, Qiu C et al. Potential therapeutic role of Co-Q10 in alleviating intervertabral disc degeneration and supressing and IL-1 $\beta$-mediated inflammatory reaction in NP cells. Int Immunopharmacol 2018; 64:424-31. (PMID: 30261465).

7. Park SN, Back SA, Park KH et al. Comparison of cochlear morphology and apoptosis in mouse models of presbycusis. Clin Exp Otorhinolaryngol 2010; 3(3):126-35. (PMID: 20978629).

8. Varela-Lopez A, Giampieri F, Battino M, Quiles JL. Coenzyme $\mathrm{Q}$ and its role in the dietary therapy against aging. Molecules 2016; 21(3):373. (PMID: 26999099)

9. Kalayam B, Meyers BS, Kakuma T, et al. Age at onset of geriatric depression and sensorineural hearing deficits. Biol Psychiatry 1995; 38(10):649-58. (PMID: 8555376). ber of participants should be conducted, together with animal experiments with ABR studies involving higher frequencies, where different doses are tested.

10. Parham K, McKinnon BJ, Eibling D, Gates GA. Challenges and opportunities in presbycusis. Otolaryngol Head Neck Surg 2011;144(4):491-5. (PMID: 21493222).

11. Donahue A, Dubno JR, Beck L. Guest editorial: accessible and affordable hearing health care for adults with mild to moderate hearing loss. Ear Hear 2010, 31:2-6. (PMID: 20040828).

12. Tavanai E, Mohammadkhan G. Role of antioxidants in prevention of age-related hearing loss: a review of the literature. Eur Arch Otorhinolaryngol 2017; 274(4):1821-34. (PMID: 27858145).

13. Heman-Ackah SE, Juhn SK, Huang TC, Weidmann TS. A combination antioxidant therapy prevents age related hearing loss in C57BL/6 mice. Otolaryngol Head Neck Surg. 2010; 143(3):429-34. (PMID: 20723783).

14. Someya S, Yamasoba T, Weindruch R, Prolla TA, Tanokura $M$. Caloric restriction suppresses apoptotic cell death in the mammalian cochlea and leads to prevention of presbycusis. Hear Res 2007; 30:207-18. (PMID: 16890326).

15. Someya S, Xu J, Kondo K, et al. Age-related hearing loss in C57BL/6J mice is mediated by Bak-dependent mitochondrial apoptosis. Proc Natl Acad Sci USA 2009; 17:106(46):19432-37. (PMID: 19901338).

16. Chung HY, Kim DH, Lee EK et al. Redefining chronic inflammation in aging and age-related diseases: Proposal of the seroinflammation concept. Aging Dis 2019; 10(2):367-82. (PMID: 31011483).

17. Salami A, Mora R, Dellepiane M et al. Water soluble coenzyme Q10 formulation $\left(\mathrm{QTER}^{\circledR}\right)$ in the treatment of presbycusis. Acta Otolaryngol 2010; 130(10):115462. (PMID: 20443731).

18. Someya S, Prolla TA. Mitochondrial oxidative damage and apoptosis in age-related hearing loss. Mech Ageing Dev 2010; 131(7-8):480-86. (PMID: 20434479). 